\title{
Facebook as a Beneficial Tool While Used in Learning Second Language Environment
}

\author{
Krzysztof Polok*, Joanna Harężak \\ University of Bielsko-Biała, Bielsko-Biała, Poland \\ Email: *sworntran@interia.pl
}

How to cite this paper: Polok, K. and Harężak, J. (2018) Facebook as a Beneficial Tool While Used in Learning Second Language Environment. Open Access Library Journal, 5: e4732.

https://doi.org/10.4236/oalib.1104732

Received: June 20, 2018

Accepted: July 16, 2018

Published: July 19, 2018

Copyright (c) 2018 by authors and Open Access Library Inc.

This work is licensed under the Creative Commons Attribution International License (CC BY 4.0).

http://creativecommons.org/licenses/by/4.0/

\section{cc) (7) Open Access}

\begin{abstract}
The article hereunder is to focus on the exact phenomenon of the usage of Social Networking Sites (SNS), more specifically the Facebook page and its potential influence on the growth of high school learners' motivation to learn a foreign language (English). The precise research findings are to be presented and discussed in detail. In an attempt to obtain as meaningful outcomes as possible, the study which is to be depicted was conducted using a mixed method. Thus, the numerical data was completed with the qualitative outcomes. Furthermore, the innovative method of teaching English is presented in detailed comparison with the traditional one.
\end{abstract}

\section{Subject Areas}

Education

\section{Keywords}

Social Networking, Facebook, High School Learners, Innovative Teaching, Motivation, English Learning

\section{Introduction}

Relating to remarkable amount of recent studies, the issue of modern technology transpires significantly useful when implemented in the learning environment ([1] [2] or [3] to name just three). Quite apart from a commonly experienced notion that modern technology (Facebook, Instagram and/or Twitter) can serve as a set of fun-providing utilities mostly, its educational aspects must not be pushed backwards. Bearing in mind the very aspect of the computerized world of these days, the Internet tools which are readily accessible on the basis of everyday life might appear efficient also when implemented in a language classroom. While, specifically, aiming attention at teenage students' encouragement 
to learn English, one ought to consider plenty of inconveniences which may occur in this case. Especially, because of the fact, the process of motivation has been accepted to be impermanent by plenty of researchers interested in this aspect (i.e. [4] [5] [6] [7] [8]).

Therefore, the teachers of young adults may keep in mind the possibility to use extra teaching tools that could be of attractiveness for their students, in case of having them constantly motivated to gain knowledge in particular fields.

\section{School Students' Motivation to Learn English}

Paraphrasing [7], the term motivation has been stated not to have only one, specific definition, although, the meaning of this exact process might be outlined as "the need to achieve a particular goal" ([5], p. 123). Obviously, one cannot be permanently motivated, while the desire to reach certain goals begins to cease. The studies conducted by [9] or, taking some more recent ones, by [8] proved that the very phenomenon of demotivation (or, even, amotivation) is not hard to occur in the educational background. Due to the fact that the process is unquestionably nonpermanent, as we already know from what was mentioned above, it also changes depending on one's age. The obvious fact is that an adult will not be identically motivated to act in comparison to a teenager, as well as a child will also have different priorities in achieving their goals. It is obvious that the aspect of motivation is vital when bearing in mind the process of learning. As this paper deals with the problem of high school students' motivation to learn English, it is worth mentioning that students of the age of adolescence are in the time of shaping their personalities as well as priorities, what is often illustrated by various (and sudden) changes [11] [12] [13]. As is the case of young learners from primary schools, all they mostly do is preparing for classes, meeting and playing with friends. In very many cases they treat school as an obligation, as this is definitely a huge part of their everyday life. The situation is pretty similar in high (i.e. secondary) schools, but the character of a teenager is not as susceptible to duties as in the case of a younger pupil. As learners get older, they are more experienced and, therefore, able to discover themselves in many matters. They have more possibilities, more goals to achieve, more activities to accomplish. In plenty of situations from a teenager life, they get to know more and more new aspects of socialization. What is more, many people, after their eighteenth birthday consider themselves old enough to decide about their lives, which-in some cases-is not necessarily prosperous.

Taking the educational issue into consideration, many adolescent learners frequently reject the process of learning. For this reason, teachers have to work hard to diversify their classes in any way that would seem interesting to their students. Undoubtedly, learning foreign languages is one of the most enjoyed subjects among high school students [14], because they want to be communicative and understand-able in their actions which often require using a given second language. Nevertheless, there always appear certain problems related to motivation, because students might just feel bored with not only the school rou- 
tine, but also their poor mood, an argument with a close person, and going deeper into various demotivating sources for learning, a bad grade or even their fatigue. Actually, each individual has their own source of discouragement. For this reason, a teacher should pay attention to all the matters that their learners find appealing, what they are involved in, what their actual forms of entertainment are often reported to be. Relating to [15], a noteworthy technique is presented in the paper; the technique of his, namely, considers the processes of teaching and learning as successful and highly prosperous when they have been found to be closely associated with the students' everyday activities.

\section{Motivation to Learn English Triggered by the Social Media}

Learning English is, beyond any doubt, aimed at achieving the proper level of communication. At this point, when comparing the interests of teenage students along with their motivation to learn English, as well as with communication, one can associate these factors with one, specific aspect-social networking sites (SNS); thus, a network that is being expanded every day by the adolescents. Going further with statistics, the most favorable SNS among the teenagers all around the world are Facebook, Instagram, Snapchat and Twitter [17]. All of these applications require active participation of their users. This way, people socialize, yet obviously using their mother tongue to do so. It gives them chances for communicating by writing messages, recording videos, commenting on different postings, what often leads to various discussions.

Foreign language teachers should note that this type of activity in the classroom could be very beneficial, due to the fact that such forms of desirable communication constantly occur. Asking students to use the English language in their posts, or any other form of activity in the social media entertainment, leave them free in the choice of subject matters, actually means doing everything the same as before, but, expectedly, in English. Therefore, weak students can learn from the better ones, and the better ones will certainly show their knowledge more willingly. For sure, setting up a private class group created on an application can also be a profitable idea. Paraphrasing [18], the youth of these days simply gets bored with the process of education and there has to be named a source to trigger them somehow. This is how the study described in this paper was carried out.

It is widely known that Facebook (and recently also Instagram and/or Twitter) has become the most popular social medium in the world [17]. As a helpful tool for learning, it was also tested many times (i.e. [1] [2] [3]). However, there are other media that can be taken into account, not so often researched and popular in terms of education, but still popular in terms of being reached for by the young citizens of the world. For example, following the statistics, Instagram is a very common application that almost every teenager makes use of. In general, the popularity of Instagram is spreading every day. You can find a lot of research on this application as helpful primarily in marketing. But its use could certainly 
prove to be helpful for students, because it is based on adding hashtags, which, in most cases, does occur in English. Just, for example, it could be incredibly helpful in learning vocabulary, which could be simply absorbed by students. Among other SNS there are also, among others, Snapchat, Twitter or YouTube. As it turns out, each of them can be used in learning as soon as the teacher finds out that students show evident interest in these applications. It is also worth noting that the teacher herself/himself should also be up-to-date with all the novelties of the digital world of her/his pupils, because it is obvious that educators should be able to take control over their students' work, not only by issuing orders but also actively participating in the process of knowledge store.

It is also commonly known that young people are constantly united with the social networks they have found liking of and, sometimes, due to this fact, they tend to neglect their school duties [19]. Consequently, they procrastinate everything they need to accomplish at school, in favor of socializing somewhere in the Internet. Kessler [3] finds the way to replace this useless act of being active in the social media background; in her interestingly written paper, one can find an explanation how to make use of social networks and, thus, learn by doing so. Kessler emphasizes the very fact that smartphones and media are not the enemies of education. Furthermore, she notices the social networks are equivalent with instant collaboration.

The method in which Facebook can be used for learning purposes, was outlined by [20] in fifty different reasons. The very first one is the aspect of fun, which has always been a significant matter taken into account in the educational field. Naturally, when the school routine is omitted and there appears an attractive differentness, students at any level feel more open towards the process of learning. Secondly, since each individual has their own type of personality, the students considered as shy, might be provided a perfect chance to accomplish various tasks of social interactions online whilst feeling more confident and complacent about their actions. Likewise, teachers might have their students expand their classroom discussions and debates into the online platform, where they actually remain connected invariably. That is, they could easily make use of the learning apps (which are, incidentally, another reason to implement Facebook in a language classroom) and freely, with no restriction, comment on different topics. Simultaneously, they acquire new vocabulary and phrases in an easy and pleasant way. What is also considered as meaningful is the aspect of quick feedback, since this exact idea would be appreciated by students without any doubt. As for the final example of the fifty reasons to use Facebook in the classroom, in his article, [20] cites a definition of informal communication. This issue might be taken into account as far as the case of improving student-teacher and teacher-student interactions is concerned.

\section{Research Objectives}

The purpose of our study was to analyze three research questions, as well as to 
confirm or reject three hypotheses that had been stated before. In furtherance of reaching the aim of the investigation, there were two groups of high school students selected and they were examined in order to compare their results from different research instruments. Each of the study objectives is specifically characterized in this section.

\subsection{Research Questions and Hypotheses}

The study that was conducted in 2018 was aimed at answering the following questions:

Q1: Are students' perceptions towards Facebook implemented in the language classroom positive or negative?

Q2: How might the application of Facebook increase students motivation to learn English?

Q3: When compared to the traditional method, is Facebook advantageous as the tool introduced in the language classes?

The above mentioned questions are to be answered in detail on the basis of both the quantitative and qualitative data gathered throughout the research. Likewise, focusing on three research hypotheses, the supposed findings are to either confirm or reject the stated assumptions (the above-mentioned steps are also appear to be necessary to elaborate a way to verify our hypotheses):

H1: Students show high eagerness towards Facebook as a language learning tool and declare higher motivation and easiness while learning L2.

H2: When smartly implemented into the language classroom, Facebook makes them more open to the target language and therefore increases their motivation to learn.

H3: Facebook transpires to be more favorable in its effects while teaching and learning English when compared to the traditional way of learning.

\subsection{Participants}

Two groups (control and experimental) of students were chosen to investigate. There were 44 Polish subjects in total with an equal amount of 22 in each group. Both groups were from two different high schools located in a town of southern Poland. The Table below (Table 1) shows more specifically described demographic data (C-control; E-experimental).

\subsection{Research Procedures}

The study took 40 lesson hours (4 hours a week). Additionally, in the case of the experimental group, the time they devoted to be online outside the school. As far as the control group was concerned, they attended traditional English classes, only with the extra implementation of a few idiomatic expressions as well as phrasal verbs. The research established a mixed method for the purpose of collecting the outcomes as meaningful as possible. Thus, the instruments chosen to gather the quantitative data were as follows: 1) previous unit test (the test from 
the unit that preceded the time of the study) and 2) current unit test (the test from the unit that were conducted after the time of the study). These instruments were chosen in order to analyze the authentic grades of the subject of two groups, relating to the time before the study took place in comparison with the time after it had finished. Furthermore, the 3) prestest, 4) test and 5) posttest were conducted in both groups, also in an attempt to evaluate the students' results. Right after the study had finished, the subjects from the experimental group were asked to indicate on 6) the Likert scale survey, whether their level of motivation has increased or not. As for obtaining the qualitative results, the study also examined 7) the classroom teacher's observation, which was meaningful for confirming the hypotheses that were stated, likewise 8) five voluntary students commentaries on the study.

\subsection{Results}

\subsubsection{The Previous Unit test Results}

Table 2 displayed beneath demonstrates the measures of central tendency and dispersion as well as, in addition, the Student's t-test esteems for the control and the experimental group outcomes from the test on the unit preceding the investigation.

As can be found in Table 2, the control group went extensively more proficient in their test from the unit going before the season of the investigation. The

Table 1. Demographic data of the research participants $(\mathrm{N}=44$; nationality: Polish).

\begin{tabular}{cccc}
\hline & C. group & E. group & Overall \\
\hline Number & 22 & 22 & 44 \\
Males & 15 & 12 & 27 \\
Females & 7 & 10 & 17 \\
Mean age & 18 & 18 & 18 \\
English learning & 12 & 12 & 12 \\
mean time (years) & & & 4.5 \\
$\begin{array}{c}\text { Facebook activity } \\
\text { mean time (years) }\end{array}$ & 5 & 4 & \\
\hline
\end{tabular}

Table 2. The measures of central tendency and dispersion and Student t-test values for the previous unit test.

\begin{tabular}{ccc}
\hline & Experimental group & Control group \\
\hline Mean & 3.41 & 4.23 \\
Median & 4.00 & 4.00 \\
Std. Deviation & 1.30 & 0.92 \\
Minimum & 1.00 & 1.00 \\
Maximum & 5.00 & 5.00 \\
t-Student Test & \multicolumn{2}{c}{$\mathbf{t}=-2.412 ; \mathrm{p}=0.020$} \\
\hline
\end{tabular}


mean mark attained in the test from the past section by the students from the exploratory group was 3.41 with a deviation of 1.30 . The center value was 4 , the minimal grade was 1 , and the maximum was 5 . The mean score of the subjects having a place in the control group was 4 , with a deviation of 0.92 . For this situation, the median even with 4 , the minimum esteem was 1 , while the maximum was 5. The estimations of the Student's $t$ test $(t=-2.412, p=0.020)$ demonstrated a critical contrast between the after-effects of the students from the trial group in correlation with the findings of the control subjects. The results of the students from the control group were essentially higher than those of from the experimental group.

\subsubsection{Current Unit Test Results}

Analogously, as in the case of the previous unit test results, Table 3 presented below demonstrates the measures of central tendency and dispersion. Obviously, the Student's t-test esteems were also counted for the control and the experimental group outcomes from the test on the unit conducted after the time of the study.

In the test performed after the examination, the normal of evaluations achieved by the experimental group was 4.18 with a deviation of 0.73 . The center esteem was 4; the most reduced score was 3 , while the highest was 5 .

On account of the subjects having a place in the control group, the normal score was identical, thus 4.18 with a deviation of 0.85 , the middle was 4 , the lowest grade was 2, while the highest was 5 . There was no distinction in the outcomes acquired by the students from the control group in comparison with the grades of the subjects belonging to the exploratory group, which is affirmed by the Student $t$-test $(t=0.000, p=1.000)$.

\subsubsection{The Previous and the Current Units Tests Results-Comparison}

Table 4, placed below presents the comparison of the grades obtained by the

Table 3. The measures of central tendency and dispersion and Student t-test values for the current unit test.

\begin{tabular}{ccc}
\hline & Experimental group & Control group \\
\hline Mean & 4.18 & 4.18 \\
Median & 4.00 & 4.00 \\
Std. Deviation & 0.73 & 0.85 \\
Minimum & 3.00 & 2.00 \\
Maximum & 5.00 & 5.00 \\
t-Student Test & & $\mathbf{t}=\mathbf{0 . 0 0 0 ;} \mathbf{p}=\mathbf{1 . 0 0 0}$ \\
\hline
\end{tabular}

Table 4. Previous \& current tests results-comparison (experimental group).

\begin{tabular}{ccccccc}
\hline & \multicolumn{3}{c}{ Previous unit test grades } & \multicolumn{2}{c}{ Current unit test grades } & \multicolumn{2}{c}{ t-Student Test } \\
\cline { 2 - 7 } & $\mathbf{M}$ & SD & $\mathbf{M}$ & SD & $\mathbf{t}$ & $\mathbf{p}$ \\
\hline Experimental group & 3.41 & 1.30 & 4.18 & 0.73 & -4.822 & $<0.001$ \\
\hline
\end{tabular}


students from experimental group. Specifically, it juxtaposes their mean averages of grades from both tests as well as the standard deviation. The Student's t-test outcomes are also presented.

On account of the experimental group, there was a critical contrast in the results achieved in the test completed before, when contrasted with the outcomes from the latest unit test, as demonstrated by the Student $\mathrm{t}$-test $(\mathrm{t}=-4.822, \mathrm{p}<$ 0.001). The acquired outcomes confirm the high adequacy of the Facebook-based technique as beneficial. The marks got by the subjects after the study were altogether higher than those acquired in the test led before the investigation.

Equivalently, Table 5 presents the comparison of the grades obtained by the students belonging to the control group. More precisely, the table correlates their mean averages of grades from both tests as well as the standard deviation. Also, the Student's t-test outcomes are displayed.

Despite what might have been expected, the Student $t$-test esteems $(t=0.568$, $\mathrm{p}=0.576$ ) demonstrate that there is no noteworthy contrast between the evaluations attained by the subjects from the control group in the test performed before in comparison with the outcomes acquired in the current test. The evaluations got in the tests by the students who were taught by the conventional technique transpired hardly noticeable.

The next table (Table 6) juxtaposes the results from the pretest and the posttest as far as the experimental group is concerned.

\subsubsection{The Pretest and Posttest Results-Comparison}

As is seen, there was a noteworthy distinction in the pretest points attained by the subjects from the experimental group, when contrasted with the outcomes they got in the post-test, which is affirmed by the Student $\mathrm{t}$-test $(\mathrm{t}=-7.541, \mathrm{p}<$ 0.001). The data demonstrates high adequacy of the imaginative showing strategy with the utilization of Facebook connected in the classroom, with regards to the students having a place in the exploratory group. The average number of points acquired by the students in the test directly after the examination was considered as significantly higher than the mean score from the pretest.

While relating to the control group, Table 7 presents exactly the same comparison as in the abovementioned experimental group, thus the control subjects

Table 5. Previous \& current tests results—comparison (control group).

\begin{tabular}{cccccccc}
\hline & \multicolumn{2}{c}{ Previous unit test grades } & \multicolumn{2}{c}{ Current unit test grades } & \multicolumn{2}{c}{ t-Student Test } \\
\cline { 2 - 7 } & $\mathbf{M}$ & SD & M & SD & t & p \\
\hline Control group & 4.23 & 0.92 & 4.18 & 0.85 & 0.568 & 0.576 \\
\hline
\end{tabular}

Table 6. Pretest \& Post test results comparison (experimental group).

\begin{tabular}{cccccccc}
\hline & \multicolumn{2}{c}{ Pretest } & \multicolumn{2}{c}{ Posttest } & \multicolumn{2}{c}{ t-Student Test } \\
\cline { 2 - 7 } & M & SD & M & SD & t & p \\
\hline Experimental group & 15.00 & 9.56 & 23.00 & 4.77 & -7.541 & $<0.001$ \\
\hline
\end{tabular}


results from the pretest are correlated with their posttest outcomes.

In the case of the control group, the Student $\mathrm{t}$-test values $(\mathrm{t}=-1.436, \mathrm{p}=$ 0.166 ) demonstrate that there is no significant contrast between the amount of points acquired by the subjects in the pretest, in examination with the post-test results. The students educated by the traditional technique got a relatively comparative score in the depicted tests.

\subsubsection{Likert Scale Survey on Motivation-Results}

The exploratory subjects were provided a 5-point Likert scale survey in which they were to indicate whether, after completing the study, their level of motivation to learn English has increased or not. The obtained results are presented in detail in Table 8.

As is found in the table, the experimental students considered only the positive responses, i.e. they demonstrated in the amount of 4 (18.2\% of them) that their motivation to learn English has slightly increased and the rest of them, consequently 18 students (81.8\%) implied that their motivation has increased significantly.

Propitiously, considering the study all the more definitely, the responses of negative content were excluded by the subjects inside and out. This implies they dismissed the potential situation of becoming demotivated, hence, that their motivation has 1 ) significantly decreased ( $0 \%$ answers) or 2 ) slightly decreased ( $0 \%$ answers). Neither did they respect the impartial circumstance, i.e. that their motivation has 3$)$ not changed at all ( $0 \%$ answers as well).

\subsubsection{The Classroom Teacher's Observation}

The exploratory students' teacher of English had been asked to bear in mind their possible change in behavior and perceptions towards the English classes. Obviously, the main aim of this way of gathering the qualitative data for the ongoing study was to check whether the level of the students' motivation has visibly increased or not. Succinctly, the teacher indicated notable difference in their

Table 7. Pretest \& posttest results—comparison (control group).

\begin{tabular}{ccccccc}
\hline & \multicolumn{2}{c}{ Pretest } & \multicolumn{2}{c}{ Posttest } & \multicolumn{2}{c}{ t-Student Test } \\
\cline { 2 - 7 } & M & SD & M & SD & t & p \\
\hline Control group & 17.00 & 9.07 & 18.00 & 6.70 & -1.436 & 0.166 \\
\hline
\end{tabular}

Table 8. Survey on motivation-results.

\begin{tabular}{ccc}
\hline Responses & Frequency & $\%$ \\
\hline significantly decreased & 0 & 0 \\
slightly decreased & 0 & 0 \\
not changed at all & 0 & 0 \\
slightly increased & 4 & 18.2 \\
significantly increased & 18 & 81.8
\end{tabular}


demeanor. Referring to the weak students, especially, thus, the students who had seemed disinterested and highly uninvolved in the classes before the time of using Facebook, they were said to have made significant progress. Additionally, the teacher noticed that conducting the speaking-oriented lessons have also become easier, as the students are eager to continue any discussion that have been raised earlier on their Facebook group. Hence, they seem more confident about their accomplishments as well as more enthusiastic about the English classes on the whole. Overall, the teacher of the experimental group approves the beneficial influence of Facebook while used in a language classroom

\subsubsection{The Students' Remarks}

As for obtaining the most meaningful results and confirming the hypotheses, five random students were requested to comment on their perceptions towards the study. Once more, the very issue of motivation change was raised, since they were asked a following question: As far as you are concerned, has your level of motivation to learn English increased after completing the study with the usage of Facebook? Justify your answer.

As transpired, five of the interviewed students unquestionably admitted that they have experienced considerable boost of their motivation level, specifically relating to learning English. While justifying their answers, the students, likewise their teacher, stated that there was a notable change in weak learners' acting. Thus, not only was it visible for the teacher but also the students themselves have noticed the difference. They really appreciated the exact idea of making use of Facebook for language learning purposes and, in addition, stated that they are willing to continue their Facebook group although the study was finished.

\subsection{Conclusions}

As specified in the Introduction to this paper, Facebook is generally recognized as a highly time-consuming source, where many Facebook users are voluntarily willing to spend plenty of time, using it to suit their subjective purposes. From this point of view Facebook should be understood as a fun-providing activity only. In our research we wanted to find out whether Facebook may also be used as an educational means, where various didactic purposes may be obtained.

Our study aimed at checking if high school learners might make use of Facebook and, simultaneously, master their proficiency and the knowledge of English. Unquestionably, the data gathered throughout the research, confirmed the hypotheses that had been stated and let us answer the research questions. From the numerical data, can be found that the experimental group, hence the group which made use of Facebook, has made noticeable progress in their achievements. The exploratory subjects bettered the control group in their results since the social networking site transpired beneficial as far as acquiring various phrases was concerned. Also, bearing in mind the survey on motivation carried out in the experimental group, the students indicated that, predominantly, their motivation had significantly increased after completing the exact study. 
As for the qualitative findings, thanks to which the hypotheses might have been confirmed more precisely, the classroom teacher of the experimental group completely agreed with the statement that Facebook was beneficial while used in a language classroom. What is more, from the students who voluntarily decided to comment on their perceptions towards the use of the exact social networking site, each claimed that they felt more motivated and confident about their actions performed during their English classes at school.

It can be concluded that, in comparison to the traditional method of learning, Facebook turned out remarkably advantageous in motivating adolescents to learn the English language. Due to this fact, teachers ought to bear in mind the very issue of implementing any differentness into their classes in order to keep their students motivated to gain the knowledge.

\subsection{Study Limitations}

\subsubsection{Presumed Study Limitations}

As far as the limitations of the study are concerned, certainly, the possible absence of the subjects during the classes is acknowledged, especially taking into consideration the exact time in which the pretest, test and posttest are to be conducted. Furthermore, the problems with mobile Internet access might appear to be one of the probable drawbacks. Although such situations are obviously considered commonplace, these might be also treated as inconveniences which are of high possibility to have an impact on the study outcomes (see also [21] for analysis). Going further, the students who are to use Facebook for the purpose of the study might not become involved enough in the tasks they are going to be provided with or they might take the undertaking facetiously. In this case, their levels of motivation and eagerness to learn English are not likely to be analyzed meaningfully. What is more, the subjects can also become too self-assured in making use of social networks while having regular classes, not only in the case of English but also other subjects they are supposed to treat in all seriousness [22] [23]. Yet, the overall research design appears to be auspicious since the sample size of both groups is identical and, likewise, in either case the course-book as well as the discussed unit is all the same.

\subsubsection{Actual Study Limitations}

Since the study consisted primarily in obtaining relevant data to be juxtaposed and compared at the end, it was crucial that selected research instruments had to be completed in detail. Specifically, the pretest, test and post-test, in the case of two groups, were carried out at the beginning, in the middle and immediately after the investigation. The control and experimental group participated in the study, with twenty-two students in each group. While carrying out the three main research instruments listed above, there were several students absent. However, they actually have accomplished the exact testing procedures, being provided with them on the subsequent lesson. Also, the limitations included quite frequent problems with the access to the Internet. Yet, this inconvenience 
was not of high influence on the study results since the students mainly made use of online tasks outside school, after the classes. Besides, unfortunately, their level of engagement on the Facebook group, was not necessarily the same as the involvement of students considered as more proficient was still more visible. The weaker students were actively engaged in the online tasks as well but it was apparent that they need more time and effort to build their confidence in making use of everyday English phrases. What is vital, is that the teacher of the group unquestionably stated, that the motivation to learn English was noticeably increased in each individual, both in the case of the better students and the weaker ones. Also, bearing in mind the students' commentaries, they themselves also found the experiment a remarkable way to become more motivated.

\section{References}

[1] Junco, R. (2012) The Relationship between Frequency of Facebook Use, Participation in Facebook Activities, and Student Engagement. Computers and Education, 58, 162-171. https://doi.org/10.1016/j.compedu.2011.08.004

[2] Language Learning. https://files.eric.ed.gov/fulltext

[3] Burt, R. (2011) The Why and How of Using Facebook for Educators. https://www.theedublogger.com/

[4] Weiner, B. (2002) Human Motivation: Metaphors, Theories \& Research. Sage Publications, Thousand Oaks.

[5] Slavin, R.E. (1997) Research on Cooperative Learning and Achievement. What We Know, What We Need to Know. Contemporary Educational Psychology, 21, 123-134.

[6] Vygotsky, L.S. (1978) Mind and Society: The Development of Higher Mental Processes. Harvard University Press, Cambridge.

[7] Gardner, C.R. (2010) Motivation and Second Language Acquisition. The socio-Educational Model. Peter Lang Publishing, New York.

[8] Dornei, Z. (2013) Motivation and "Self-Motivation". The Psychology of the Language Learner: Individual Differences in Second Language Acquisition. Lawrence Erlbaum Associates, Mahwah.

[9] Vijchulate, B., Lee, G.S., et al. (1985) A Survey of Students, Motivation for Learning English. RELC Journal, 16, 68-81. https://doi.org/10.1177/003368828501600106

[10] Moore, R. (2007) Academic Motivation and Performance of Developmental Education Biology Students. Journal of Developmental Education, 33, 24-26.

[11] Midgley, C. (1989) Motivation and Middle Level Schools. In: Pintrich, P.R. and Maehr, M.L., Eds., Advances in Motivation and Achievement. Motivation in the Adolescent Years. JAI Press, Stamford, 77-86.

[12] https://www.kqed.org/mindshift/14271/50-reasons-to-invite-facebook-into-your-cl assroom

[13] Goodenow, C. (1993) Classroom Belonging among Early Adolescent Students: Relationships to Motivation and Achievement. The Journal of Early Adolescence, 13, 21-43. https://doi.org/10.1177/0272431693013001002

[14] https://www.statista.com/topics/1164/social-networks/

[15] Woodburn, J.H. (1977) Using Applied Chemistry to Tackle Motivation Problems. Journal of Chemical Education, 54, 763. https://doi.org/10.1021/ed054p763 
[16] Dörnyei, Z. (2005) Motivational Strategies in the Language Classroom. Cambridge University Press, Cambridge.

[17] http://ec.europa.eu/eurostat/statistics-explained/index.php/Foreign_language_learn ing_statistics

[18] Deci, E.L. and Ryan, R.M. (2008) Self-Determination Theory: An Approach to Human Motivation and Personality. University of Rochester Press, Rochester.

[19] https://www.huffingtonpost.com/2014/05/27/student-procrastinating-statistics_n_5 399284.html

[20] Barseghian, T. (2011) 50 Reasons to Invite Facebook into Your Classroom. http://mindshift.kqed.org/2011/08/50-reasons-to-invite-facebook-into-your-classro om

[21] Weiner, B. (1979) A Theory of Motivation for Some Classroom Experiences. Journal of Educational Psychology, 71, 3-25.

[22] https://mashable.com/2010/09/29/social-media-in-school/\#L3VG3JTc4qqQ

[23] Harwood, C. and Blackstone, B. (2012) Using Facebook to Extend Learning into Students' Digital Lives. 